\title{
UM CONTO DE GADDA, QUASE SINFONIA
}

\section{Julia Marchetti Polinesio}

\section{LA MAMMA}

Esse conto de Carlo Emilio Gadda é um fragmento do romance "La cognizione del dolore", mais precisamente, o início da segunda varte, composto entre 1938-1941, mas aparecido em edição definitiva somente em 1963, em Einaudi, Torino. Sob essa mesma forma de conto o fragmento já fazia parte de "Novelle dal Ducato in fiamme", Firenze, Vellecchi, 1953, e passou depois, inalterado, ao volume "Accoppiamenti giudiziosi", Milano, Garzanti, 1963.

A ação do romance desenrola-se num imaginário país da América do Sul, entre os anos de 1925 e 1933, daí os nomes geográficos espanhois e os vocábulos inspirados nessa língua, que, como veremos, Gadda às vezes, emprega .

A personagem é a figura da mãe, velha e só, porque o filho mais moço havia morrido na guerra e o mais velho, "che andava i cammino degli uomini", vivia afastado de casa. Trata-se de romance autobiográfico, mas a realidade transcendente é, no caso, o que nos importa conhecer na sua mais profunda vitalidade artística.

O elemento fundamental do conto é o tempo, tomado nas duas dimensões, humana e eterna, e nessa atemporalidade imerge a mãe, símbolo trágico, universal e eterno da maternidade. O tempo presente the é quase estranho, sugerido em contraste com o seu verdadeiro tempo, todo interior:

"ma che cosa era il sole? quale giorno portava? sopra $\mathrm{i}$ latrati del buio. Ella ne conosceva le dimensioni e l'intrinseco, la distanza dalla terra, dai rimanenti pianeti tutti: e il loro andare e rivolvere; molte cose aveva imparato e insegnato: e i matemi e le quadrature di Keple:o che perseguono nella vacuità degli spazi senza senso l'elisse del nostro disperato dolore" 
Aí está também a transfiguração matemática da realidade sensível, a introjeção do mundo externo, do explicável no inexplicável, a representação do infinito.

O sol e a luz, símbolos da vida e da realidade quotidiana -

"e intorno alla casa si vedeva ancora la campagna, il sole" -

aparecem em oposição ao mundo sombrio em que vive a mãe, caracterizado por termos que sugerem esse estado de pavor:

"orribile, pauroso (pavoroso), tetro, orrore, tenebra, secolitenebra, ter.ibilmente, ferocemente"

A sugestão de trevas, de horror, adquire maior intensidade quando tais palavras, entre vírgulas ou no fim da frase, são como que destacadas e vibrantes: bilmente"

"una scheggia di tenebra, orrenda" - "lontani i figli, terri-

A dimensão da tragédia é dada pelos símbolos:

"fulmine, uragano (ameaça, destruição) - muro (limitação) tarlo (= cupim; corrosão) - scorpione, moscone (morte) cipressi (cemitério) - mosche (usado com insistência, ora como solidão, abandono, ora como morte)" novo

A morte é presença constante, desde a evocação do filho mais col volto ridonato alla pace e alla dimenticanza, privo di ogni risposta, per sempre"

até a própria condição da mãe que, não pertencendo mais ao mundo dos vivos, está imersa num interregno de sombras:

"non era piú persona, ma ombra"

O movimento descendente, que preludia a morte real, é por isso usado com tanta insistência:

"Ed ella si raccolse come poteva nella sua stremata condizione a ritrovare un rifugio, da basso, nel sottoscala: scendendo, scendendo, in un canto" — "scendendo, scendendo, giú, giú, verso 
il buio e l'umidore del fondo" - "Le dita incavatrici di vecchiezza parevano stirare giú,giú, nel plasma del buio, le fattezze di chi approda alla solitudine"

Note-se também a insistência com que Gadda repete os indicadores do movimento descendente, força contra a qual não é possível resistir. Arrastada para a consumação do seu destino, a mãe, no entanto, não compreende a razão desse sofrimento e indaga repetidas vezes: "perchè, perchè. " Usando essas interrogações contínuas Gadda molda sua personagem numa angústia que, quase infantil, não pode compreender o que acontece:

"la tenebra delle cose e delle anime areno un torbido enigma, davanti a cui si chiedeva angosciata (ignara come smarrita bimba) perché, perché"

A linguagem, em correspondência ao tema trágico e clássico é também clássica, coesa, límpida, patética, sem as distorções lingüísticas usadas em outras obras do autor Predominam aqui termos eruditos: "rancura, calura, remigare, capegli" e arcaismos: "famiglio (servidor doméstico), spera (por sfera, como em Dante), genti (cuja carga histórica o próprio Gadda explica numa nota especial). Apenas uma quebra dessa coesão da linguagem está nos termos de inspiração espanhola, evocadores do ambiente geográfico em que se desenrola a ação: un bicchiere di Nevado, naranza, por suerte, Tierra Caliente, Pequeño.

Nessa transfiguração da realidade o clima supra-real e cósmico está nas metáforas quase ilimitadas de todo o conto. As mais impressionantes, mais características e de maior efeito são as que se referem ao tempo, na dimensão atemporal já aludida:

"il tempo dissolto - i giorni vuoti - i latrati del buio - la nullità stupita dello spazio - il vuoto delle cose - la buia voce dell'eternità - il fulgore del tempo - una favilla dolorosa del tempo - una scheggia di tenebra"

Tantas são, que transformam, por assim dizer, todo o conto numa única metáfora, o que coincide com a própria condição da poesia.

O conto divide-se em três partes, que eu gostaria de chamar "movimentos", de tal forma sua composição, desde as primeiras palavras "vagava, sola, nella casa" repetidas adiante mais duas vezes como motivo melódico evocativo de solidão e angústia, lembra a de uma sinfonia. Não posso deixar de pensar na $6 .^{\text {a }}$ Sinfonia de Beethoven, pela 
semelhança profunda que existe entre o temporal da música e do conto, e a bonança sucessiva. O terror dos homens pelas tormentas, a angústia provocada por elas, a alegria ao rever o sol, que não são invenções particulares mas sentimentos existentes no subconsciente de cada um e transmitidos com o patrimônio coletivo da humanidade, foram captados pelo gênio criador e transformados em arte.

A primeira parte - ou movimento - do conto inicia com sugestões de ameaça:

"- il cielo, cosí vasto sopra il tempo dissolto, si adombrava talo a delle sue cupe nuvole; che vaporavano rotonde e bianche dai monti e cumulate e poi annerate ad un tratto parevano minacciare chi è sola nella casa _-"

e aumentam em intensidade até chegar a paroxismos de loucura. $O$ temporal, aqui, é a manifestação exterior, a materialização da tragédia vivida pela mãe.

Com uma sugestão de esperança e de luz dada pela lembrança do filho vivo inicia a segunda parte -

"Questo nome le si posò lieve sull'animo: e fu cara parvenza, suggerimento quasi di mattino e di sogno, un'ala che trasvolasse, una luce" -

Lembra-nos o Allegretto da Pastoral, em que o sol e a bonança devolvem aos homens a tranqüilidade perdida. À medida que a luz se torna mais intensa e mais doce a solidão é interrompida por uma presença humana:

"Il zoccolante passo del contadino risuonò sull'ammatonato di sopra Rinfrancata ella rivide chiarità dolci e lontane del paese e nella memoria le fiorirono quelle paro'e di sempre: "Apre i balconi - apre terrazzi e logge la famiglia"

Inspirado nesses versos de Leopardi, do Canto "La quiete dopo la tempesta", Gadda compõe um interlúdio lírico de tranquiilidade e paz, e propositadamente reconstitui o clima criado por aquele poeta ao sugerir a alegria pela volta dos homens ao trabalho, depois do temporal. Encontramos a mesma sensação de paz no Allegretto da Sinfonia de Beethoven que, estranhamente, esse conto recorda.

A semelhança sentida entre o conto e a Sinfonia Pastoral, bem como a semelhança intencional que Gadda criou com a citada lírica de Leopardi nos evidencia uma decorrência de raízes que alimentam 
a criação artística individual, fundamentadas no inconsciente coletivo comum a todos os homens. A locução adverbial "di sempre" que precede os versos de Leopardi indica que estes, vindos inconscientemente à memória da personagem, ultrapassaram o poeta, porque se incorporaram na alma do povo italiano tornando-se parte de um patrimônio comum.

$\mathrm{Na}$ parte final do conto a similitude entre este e $6 .^{\text {a }}$ Sinfonia acaba. Enquanto Beethoven cria um clima de luta e esperança, Gadda recai na tragédia.

A mãe, depois de uma pausa, mergulha novamente no sofrimento inexorável. Após o retorno ilusório ao mundo dos vivos, uma breve passagem ainda de esperança, conduz à $3 .^{\mathrm{a}}$ parte, em que se cumpre $\mathrm{e}$ se consuma o seu destino trágico:

"Le sembrò di assistervi ancora dalla terrazza di sua vita, oh! ancora, per un attimo, di far parte della calma sera. Si sentí ripresa nel flusso antico della possibilità, della continuazione: come tutti, vicina a tutti"

Mas a ilusão logo se desfaz. Fecham-se para ela as possibilidades de continuação e de vida:

"Il volto in quelle pause le si pietrificava nell'angoscia nessun battito dell'anima era piú possibile. non era piú persona, ma ombra"

Não luta mais. "Congiunse le mani", e, vítima, aceita passivamente o seu destino.

Temos nessa figura gaddiana a encarnação da mãe universal, que vive no substrato da tradição cultural da humanidade desde os seus primórdios até hoje, com todas as feições adquiridas e modificadas pelo processo evolutivo do pensamento humano, mas imutável, sempre, na sua unidade trágica. E esta, como veremos, assume vários aspectos externos, sem contudo se dissolver, mantendo, ao contrário, sua perfeição intrínseca.

O vulto épico da mãe, nos momentos de luta contra o destino que lhe rouba o filho prediletto, ao lembrar-se do segundo vislumbra uma possibilidade de salvação. Mas este momento é fugaz e transitório porque logo depois o desfecho já está cumprido:

\footnotetext{
"nessun battito dell'anima era piú possibile .. non era piú persona, ma ombra"
} 
As figuras da tragédia grega não compreendem a causa do seu sofrimento, assim como não a compreende a personagem de Gadda, que se pergunta angustiada:

"perchè.. perché. ignara come smarrita bimba"

Entretanto, a consecução do destino nesta mãe não se reduz a uma consciência puramente trágica, iluminada apenas pelo mito, porque existe em nosso conto a relação da criação poética com o acontecimento real: ela sofre pela ausência do amor perdido mas também pela distância que a separa de Gonzalo, seu filho vivo. A unidade desse clima trágico não recai expressamente sobre a personagem principal, mas enfatiza a interdependência dos caracteres e contrapõe ao universal a singularidade da estória. Vemos assim que gradativamente, por partes, encontra-se nessa "mãe" de Gadda, a contrafação das figuras trágicas através dos vários "tempos" da história.

A figura da mãe torna-se também virgiliana quando passa do desespero em que vive aos momentos líricos de ascensão e esperança, o que se pode observar melhor em toda a segunda parte do conto. No movimento ascendente do seu retorno ao mundo dos vivos passa do clima trágico para um lirismo que no mundo antigo era desconhecido. Supera "virgilianamente" a inexorabilidade do destino quando, das profundezas do seu sofrimento, tem o vislumbre de que seu sacrifício, unido ao de outros seres, talvez não seja completamente vão:

\footnotetext{
"Forse, cosí, l'atrocità del suo dolore non sarebbe vana a Dio"
}

Conforma-se a uma vontade superior e, ao unir as mãos "congiunse le mani", emerge de uma profunda dimensão cósmica, antiga e cristã, para enraizar-se na mais atual e feminina modernidade de todos nós.

Para terminar cito Gadda numa de suas expressões:

"L'adozione del linguaggio è riferibile a un lavoro colletivo, storicamente capitalizzato in una massa idiomatica, in una deformazione; questa esperienza insomma travalica i confini della personalità e ci dà modo di pensare a una storia della poesia in senso collettivo"

Com isto completamos o ciclo deste trabalho coletivo historicamente capitalizado na massa idiomática, que é o desenvolvimento supremo da arte humana. No nosso caso a linguagem poética, de for- 
mação que exorbita a personalidade, expõe o mundo da poesia na sua maior dimensão humana. E a própria humanidade que nos explica sua história. (*)

${ }^{*}$ ). - Este artigo foi elaborado sobre a leitura de "La mamma" ce Carlo Emilio Gadda in Accopiamenti Giiudiziosi, Milano, Garzanti, 1963, : C. E. Gadda "I viaggi la morte", Milano, Garzanti, 1958. 